\title{
高強度鋼のインデンテーション法による局所カ学特性評価*
}

\author{
小森貴史 ${ }^{* 1}$ ，金田 忍 ${ }^{* 2}$ ，小川武史 ${ }^{* 2}$, 坂中則暁 ${ }^{* 3}$, 松原幸生 ${ }^{* 3}$
}

\section{Evaluation of Local Mechanical Properties of High Strength Steels by Indentation Method}

\author{
Takafumi KOMORI ${ }^{*}$, Shinobu KANEDA, Takeshi OGAWA, \\ Noriaki SAKANAKA and Yukio MATSUBARA \\ ${ }^{*}$ Graduate School of Aoyama Gakuin Univ., Dept. of Mechanical Engineering \\ Fuchinobe 5-10-1, Chuo-ku, Sagamihara, Kanagawa, 252-5258 Japan
}

High strength steels are used for various important components such as rolling bearings to ensure safety. Strength designs for these components require material properties at the local areas. The objective of the present study is to evaluate the local mechanical properties of high strength steels by the dual-indenter method. Non-dimensional $\Pi$ function is developed for 118 degree trigonal pyramid indenter using finite-element method. Dual-indenter method is conducted by indenters with the apex angles of 115 and 118 degrees for SUJ2 and SUJ3. The results reveal that good agreements are achieved between stress-strain curves of tensile testing and those of the dual-indenter method. The local mechanical properties are evaluated by the dual-indenter method for induction-hardened and carburized components. There are some differences in stress-strain curves at the locations of the components by the influence of the heat treatments.

Key Words : Hardness, Stress-Strain Measurement, Bearings, Dual-Indenter Method, Local Material Properties, High Strength Steels

\section{1. 緒言}

転がり軸受などの保安部品には，強度を向上させるために全体焼入れを施すものと，強度が必要な部位にのみ 高周波焼入れや浸炭焼入れなどの表層硬化を施すものがある. 表層硬化した部位は局所的に材料特性が変化して おり，力学特性評価を行うにあたり，熱処理部のみを対象とした局所的な評価を行うことが必要とされる．これ までにインデンテーション法を用いて局所的な力学特性を評価する手法として 2 圧子法 ${ }^{1}$ が提案されている. 著 者の 1 人（小川）は様々な材料に対して 2 圧子法を適用することで力学特性評価を行ってきた ${ }^{2)}$. しかし, 高強 度な軸受鋼に対しての推定は，引張試験結果と一致しない場合のあることが明らかとなった，そこで，本研究で はインデンテーション法と有限要素法 (FEM) 解析を用いて高強度材料の力学特性を推定できる方法を検討した.

\section{2. 供試材および試験片}

供試材の高炭素クロム軸受鋼 SUJ2 およびSUJ3 の化学成分を表 1 に示す. 試験片は各材料に対して標準的な全 体焼入れを施した後, $180 \sim 350^{\circ} \mathrm{C}$ で焼戻したものを用いた. また, 高周波焼入れ, 浸炭焼入れした部品も試料と した．試料表面はエメリペーパーで研磨後にバフ研磨，ダイヤモンドペーストで機械研磨を行った。

\footnotetext{
* 原稿受付 2011 年 9 月 21 日

*1 学生員, 青山学院大学大学院（†252-5258 神奈川県相模原市中央区淵野辺 5-10-1)

*2 正員, 青山学院大学理工学部（干252-5258 神奈川県相模原市中央区淵野辺 5-10-1）

*3 NTN (株)（广511-0867 三重県桑名市陽だまりの丘 5-105)

E-mail: ogawa@me.aoyama.ac.jp
} 
Table 1 Chemical compositions (mass \%)

\begin{tabular}{ccccccccc}
\hline & $\mathbf{C}$ & Si & Mn & P & S & Ni & Cr & Cu \\
\hline SUJ2 & 1.02 & 0.27 & 0.43 & 0.014 & 0.007 & 0.05 & 1.48 & 0.09 \\
SUJ3 & 0.99 & 0.47 & 1.06 & 0.014 & 0.006 & 0.07 & 1.06 & 0.14 \\
\hline
\end{tabular}

\section{3. 試験機および試験条件}

試験には島津ダイナミック超微小硬度計 DUH一W201 を用いた．各条件についてインデンテーション試験を 6

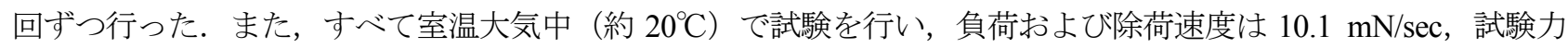
は $1961 \mathrm{mN}$ とした。 なお，三角錐圧子の稜間角 $\phi$ は $100^{\circ} ， 115^{\circ}$ および $118^{\circ}$ のものを用いた.

\section{4. インデンテーション試験}

\section{$4 \cdot 12$ 圧子法}

本研究では 2 圧子法を適用するにあたり ${ }^{2)}, \phi=100^{\circ}$ および $115^{\circ}$ に加えて新たに $118^{\circ}$ の三角錐圧子を用いる. ここで，圧子の投影面積と $h$ の比が等しい頂角 $\theta$ の円錐圧子により，以下の解析を行った，一般に，押し込み力 $F$ と押し込み深さ $h$ は $F=C h^{2}$ の関係にあり, 次元解析を行うことで次式の関数形で表される.

$$
F=F\left(E^{*}, n, \sigma_{r}, \theta, h\right)
$$

ここで， $E^{*}$ は複合ヤング率， $n$ は加工硬化指数であり，圧子の弾性変形による影響を含んでいる． $\sigma_{r}$ は代表応力 と呼ばれ塑性変形領域を特徵付ける応力である. 式(1)にП理論を適用すると，次式を得る.

$$
\frac{F}{\sigma_{r} h^{2}}=\frac{C}{\sigma_{r}}=\Pi\left(\frac{E^{*}}{\sigma_{r}}, n, \theta\right)
$$

この関数Пをそれぞれの $\phi$ の圧子について求め, 2 種類の圧子で試験を行い, 関数Пと実験結果の負荷過程の $F$ に対する $h^{2}$ の傾き $C$ を用いることによってそれぞれの圧子の代表応力一代表ひずみ関係が得られる. この 2 点の

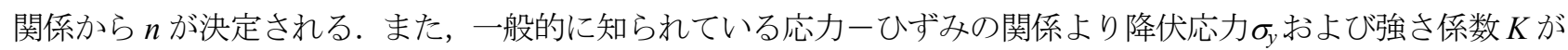
次式より得られる。ここで， $\varepsilon_{r}$ は代表ひずみである.

$$
\sigma_{r}=K \varepsilon_{r}^{n} \quad \sigma_{r}=\sigma_{y}\left(1+\frac{E}{\sigma_{y}} \varepsilon_{r}\right)^{n}
$$

\section{$4 \cdot 2$ 有限要素法解析}

2 圧子法を用いて力学特性評価を行うにあたり, 新たに作成するП関数の解析には, 汎用非線形構造用解析プ ログラム MSC. MARC Mentat 2005 を使用した. これまでに，三角錐圧子によるインデンテーション試験を行う場 合，圧子の梁さ一投影面積比が同一の円錐圧子に置き換えた軸対称モデルによる解析と，三角錐圧子の 3 次元解 析の結果が同等であることを確認している ${ }^{3)}$. FEM 解析は $\phi=118^{\circ}$ の圧子に対して頂角 $\theta=77.37^{\circ}$ の円錐圧子を 模擬した要素数 2549 , 節点数 2658 の軸対称モデルとして解析を行った. 解析モデルを図 1 に示す. 新たにП関 数を作成するにあたり，使用した材料パラメータはヤング率 $E=50 \sim 300 \mathrm{GPa}$ ，ポアソン比 $v=0.3$, 降伏応力 $\sigma_{y}$ $=0.1 \sim 5.0 \mathrm{GPa}$, 加工硬化指数 $n=0.1 \sim 0.5$ の範囲で合計 72 通りの解析を行った.

解析によって得られた $E^{*} / \sigma_{r}$ と $C / \sigma_{r}$ の関係を図 2 に示寸. 解析結果は解析条件の加工硬化指数 $n$ の值ごとに一 本の曲線で示される. このとき， $\varepsilon_{r}$ の決定には $\varepsilon_{r}=0.001$ ごとにフィッティングの検討を行い, $\phi=118^{\circ}$ の圧子 に対して $\varepsilon_{r}=0.020$ を選しだ. この結果, $E^{*} / \sigma_{r}$ と $C / \sigma_{r}$ の関係は, 加工硬化指数 $n$ の值に依存しない 1 つの曲線 で表され，無次元関数 $\Pi_{118}$ が次式として得られた.

$$
\prod_{118}=\frac{C_{118}}{\sigma_{r 118}}=43.25 \ln \left(\frac{E^{*}}{\sigma_{r 118}}\right)-55.90
$$




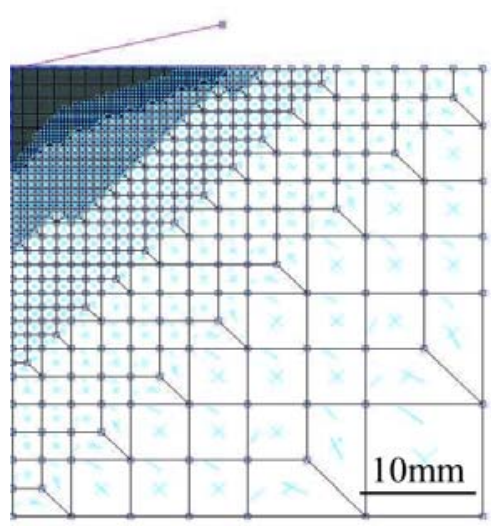

Fig.1 Model for FEM analysis.

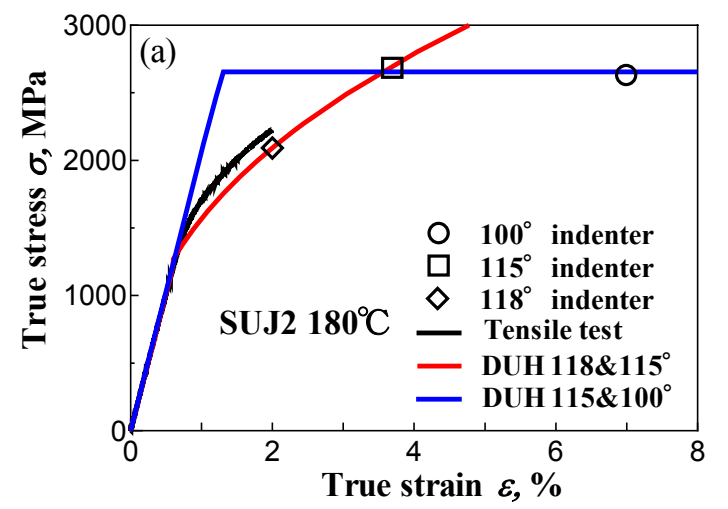

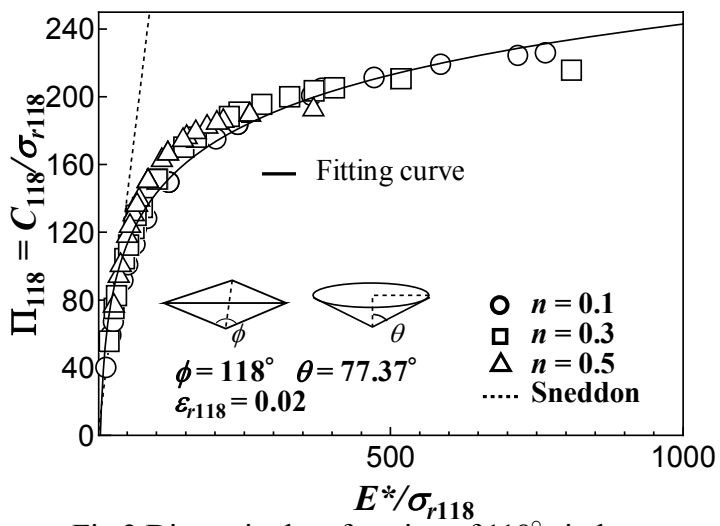

Fig.2 Dimensionless function of $118^{\circ}$ indenter.

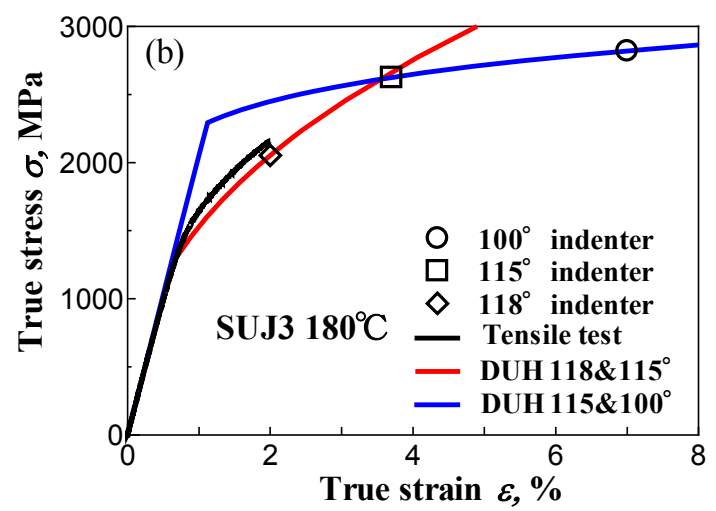

Fig.3 Stress-strain curves obtained by tensile testing and dual-indenter method for SUJ2 (a) and SUJ3 (b).

\section{5.実験結果および考察}

\section{$5 \cdot 1$ 軸受鋼の力学特性評価}

新たに作成した $118^{\circ}$ 圧子の川関数を使用して 2 圧子法による力学特性評価を行った. $180^{\circ} \mathrm{C} て ゙$ 焼戻しをした SUJ2 およびSUJ3 に対して $\phi=115^{\circ}$ と $118^{\circ}$ および $100^{\circ}$ と $115^{\circ}$ 圧子を用いた結果を図 3 に示す. $115^{\circ}$ と $118^{\circ}$ 圧子を用いた試験では引張試験結果に近い結果が得られていることが確認できる．一方， $100^{\circ}$ と $115^{\circ}$ 厚を 用いた 2 圧子法では引張試験から大きく離れた結果となった. 図 4 および図 5 に 2 圧子法より求められた降伏応 力 $\sigma_{y}$ および加工硬化指数 $n$ を示寸. $115^{\circ}$ と $118^{\circ}$ 圧子での結果は引張試駼結果と近い值が得られており, 力学特 性の焼戻し温度依存性が評価できていることから， $115^{\circ}$ と $118^{\circ}$ 圧子での 2 圧子法の有効性が確認できる.

$100^{\circ}$ と $115^{\circ}$ 圧子を用いた試験結果が引張試験と大きく異なる結果となった原因を検討するため, 圧痕の観察 を行った. 図 6 にそれぞれの $\phi$ の圧痕写真と AFM 観察結果を示す. $\phi$ が小さくなるにつれて圧痕周辺のパイル アップ量が増加していくことが確認できる. パイルアップはП関数を作成する FEM 解析で十分にシミュレート できておらず，顕著なパイルアップの発生が $100^{\circ}$ 圧子を用いた 2 圧子法で有効な結果が得られなかった原因と 考えられる.

\section{$5 \cdot 2$ 表層硬化部品の力学特性評価}

炭素鋼 S53C に高周波焼入れ，クロム鋼 SCr420H に浸炭焼入れを施した部品から切り出した試料に対して，局 所力学特性評価を行った. このような試験片に対して局所力学特性評価を行うにあたり, 熱処理の影響が及んで いる範囲を特定する必要があるため, 硬さ分布を調べた. ビッカース硬さ $H V$ の分布を図 7 および図 8 に示す. 試験力は $1961 \mathrm{mN}$ であり, 各図の写真中に示した矢印の方向に等間隔で測定した. 図 7 に示寸高周波焼入れ部品 の $H V$ が 275〜 715 であるのに対し, 図 8 の浸炭焼入れ部品の $H V$ は 340 623 の分布となっており, 熱処理方法 による $H V$ の差異が確認できる. 

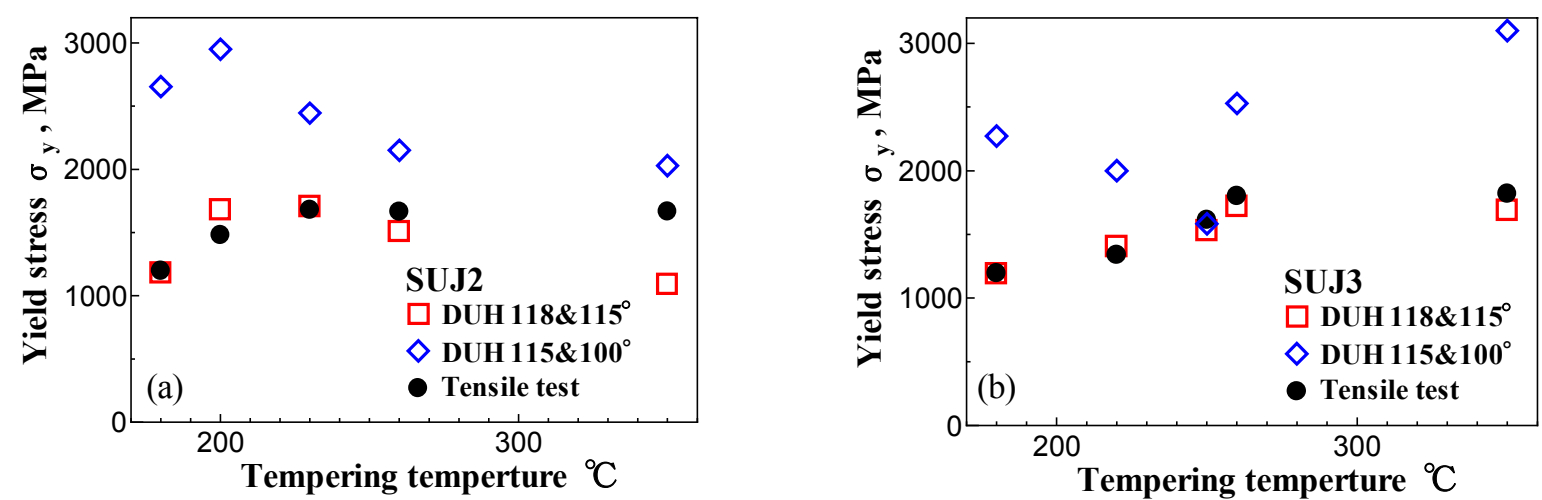

Fig.4 Results of yield stresses obtained by dual-indenter method for SUJ2 (a) and SUJ3 (b).
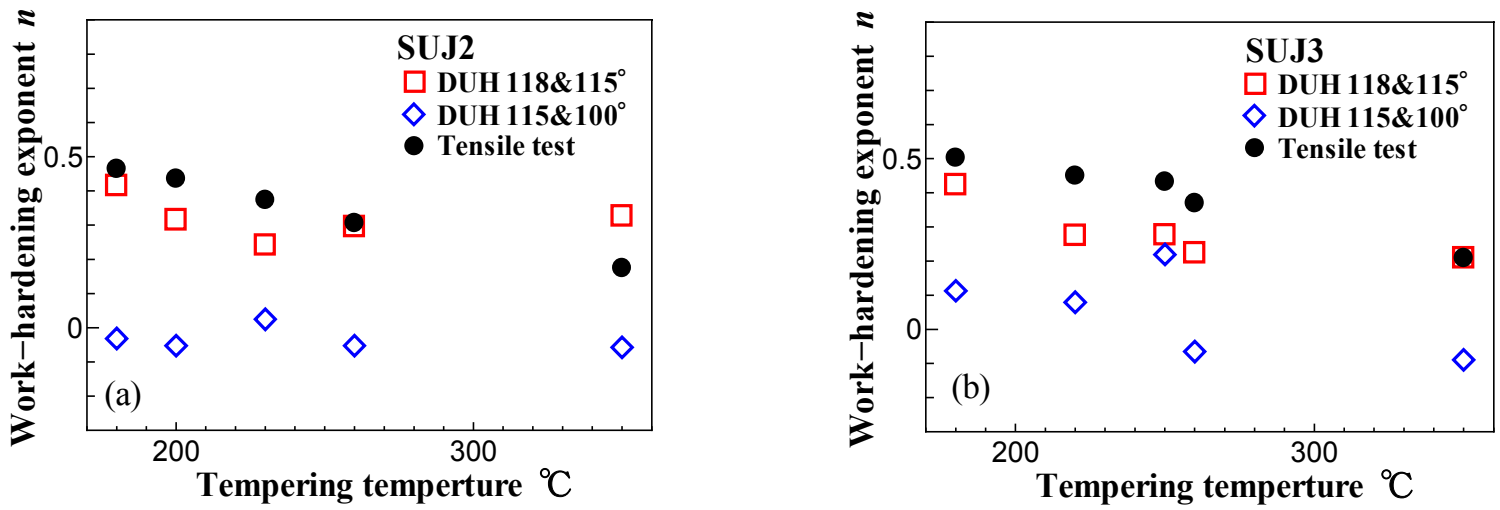

Fig.5 Results of work hardening exponents obtained by dual-indenter method for SUJ2 (a) and SUJ3 (b).
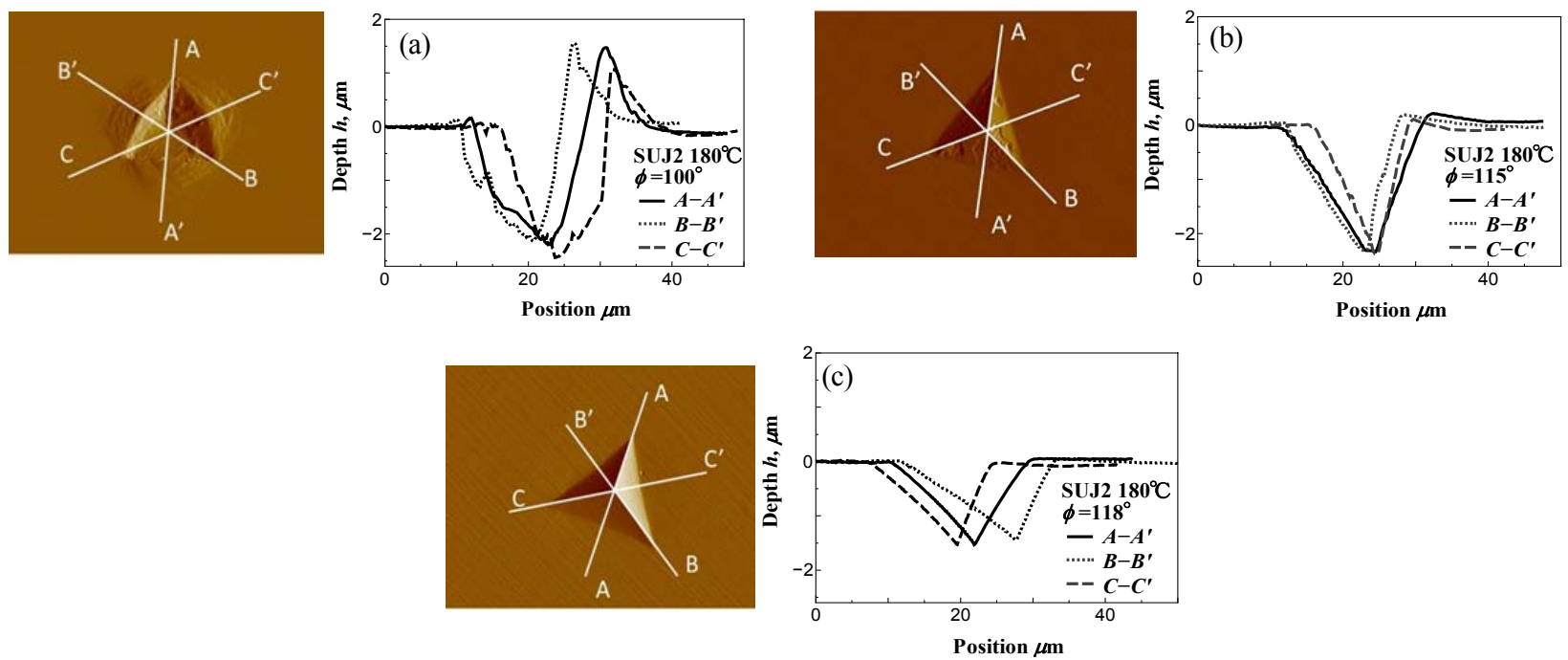

Fig.6 Shapes of impressions and height profiles measured by AFM formed by $100^{\circ}$

(a), $115^{\circ}$

(b) and $118^{\circ}$ (c) indenters.

$H V$ が 600 以上の領域を「高硬度」，400 以下の領域を「低硬度」と定義して 2 圧子法により局所力学特性評価 を行った. インデンテーション試験には $115^{\circ}$ および $118^{\circ}$ 圧子を用いた。困 9 および図 10 にその結果を示す. 高硬度領域での試験結果は降伏応力が大きく，硬さの大小と降伏応力の対応関係が確認できる．また，高周波焼 入れ部品と浸炭焼入れ部品の高硬度領域を比較したところ高周波焼入れ部品の硬さが高く，降伏応力も大きくな った。低硬度領域では高硬度領域とは異なり，浸炭焼入れ部品の方が硬さも降伏応力も大きくなっていることが 確認できる. 


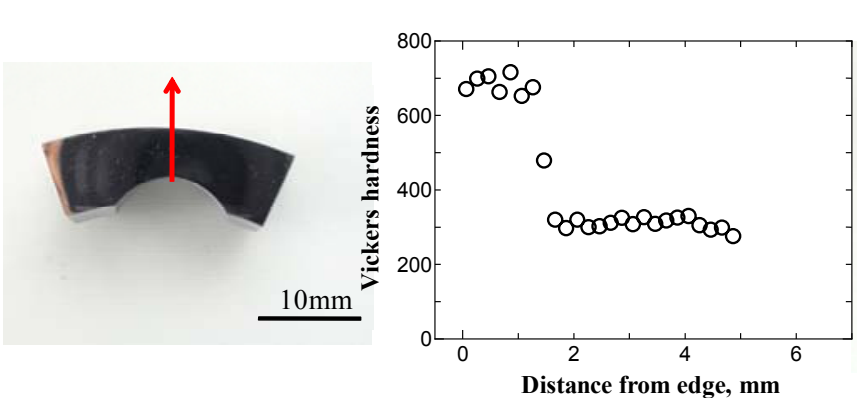

Fig.7 Shape and hardness distribution chart of inductionhardened specimen.

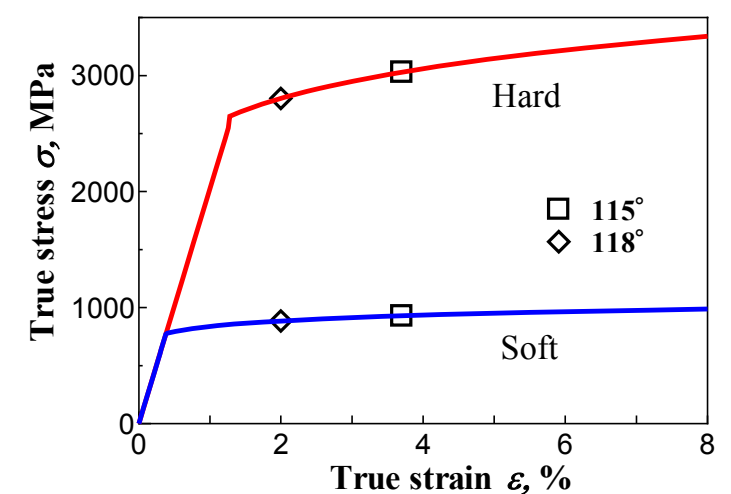

Fig.9 Stress-strain curves of induction hardened specimen.

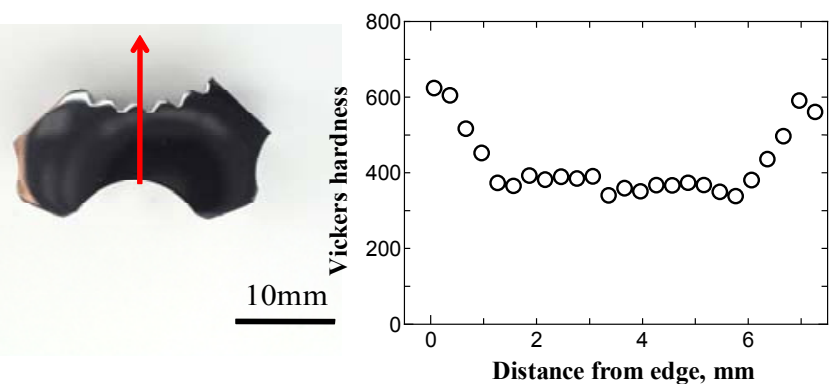

Fig.8 Shape and hardness distribution chart of carburized specimen.

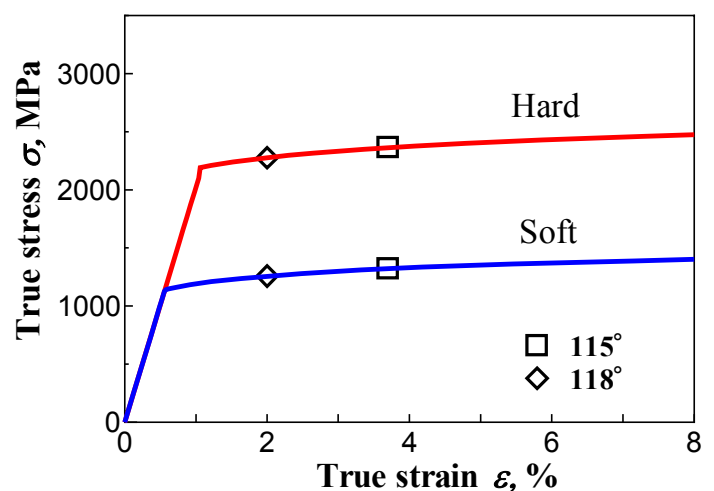

Fig.10 Stress-strain curves of carburized specimen.

高周波焼入れは表面のみを硬化させ，内部はもとの組織の状態となる，一方，浸炭焼入れは表面が硬化し，内 部の硬度もやや高くなる. 得られた試験結果はそれぞれの熱処理の特徵をよく示しており, 熱処理の影響に応じ て局所的な $\sigma-\varepsilon$ 曲線の明確な差として示すことができた.

\section{6. 結 言}

1) 様々な熱処理を施した高強度鋼の試験片に対して, $115^{\circ}$ と $118^{\circ}$ 圧子での 2 圧子法により引張試験の結果 とほぼ同等な $\sigma-\varepsilon$ 曲線を得ることができた。

2) 表層硬化部品の力学特性評価において, 高周波焼入れおよび浸炭焼入れの熱処理の相違が局所的に求めた $\sigma-\varepsilon$ 曲線から確認できた.

3） $100^{\circ}$ 圧子の圧痕周辺にはパイルアップが確認された. 圧痕周辺にパイルアップがあると, $F-h$ 曲線が影響 を受け，2 圧子法が適用できなくなる．

4) 2 圧子法により得られた $\sigma-\varepsilon$ 曲線を実機の解析に使用することで, 従来よりも詳細な弾塑性解析を行うこ とが可能になる.

\section{文献}

（1）小笠原永久, 巻口和香子, 千葉矩正, “複数の三角錐圧子押込みによるべき乗硬化材の塑性特性評価法”, 日本機械 学会論文集 A 編, Vol. 70, No.698 (2004), pp.1529-1534.

(2) Akio Yonezu, Takahashi Ogawa and Mikio Takemoto, Key Engineering Materials, Vols. 353-358, pp.2223-2226 (2007).

(3) 大野卓志, 米津明生, 小川武史, 秋光 純, “インデンテーション法による微小領域の力学特性および強度評価”, 材料試験技術, Vol.49, No.3(2004), pp.149-156. 